\title{
MÁRIO DE ANDRADE E A CULTURA POPULAR: "BRIGA DAS PASTORAS", LITERATURA E FOLCLORE
}

MÁRIO DE ANDRADE AND POP CULTURE: "BRIGA DAS PASTORAS" ["ROW OF THE SHEPHERDESSES"], LITERATURE AND FOLKLORE

Valter Cesar Pinheiro*

RESUMO: Dentre os múltiplos campos de atuação cultural aos quais Mário de Andrade fervorosa e habilmente se aplicou, um dos mais realçados e estudados pela crítica é o ligado ao folclore e à cultura popular. Destacam-se, na fecunda produção do escritor sobre as ma-

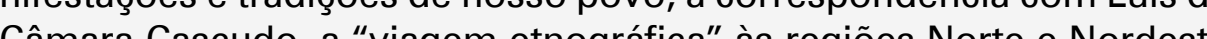
Câmara Cascudo, a "viagem etnográfica às regióes Norte e Nordest os estudos de fôlego sobre a música e a dança brasileiras. Na esfera ficcional, sobressai a rapsódia Macunaima. O interesse do autor pelo folclore nordestino tambem aparece, de forma vigorosa e lancinante, em um instigante conto da maturidade pouco conhecido, "Briga das Pastoras", cujo narrador, "turista aprendiz" em viagem a Pernambuco, revela possuir, tal qual Mário, sollidos conhecimentos metodológicos epistemológicos em Etnologia e Etnografia. Mário, no entanto, deixou registrado em nota o desejo de que o conto năo fosse publicado em livro. Por quê? A alusăo à atitude de inteligencia nacional eminentemente cafajeste" no final do apontamento parece indicar, a despeito dos significativos traços autobiográficos que permeiam a narrativa, disparidade entre os pontos de vista do autor e do narrador nos âmbitos estetico e ideológico.

PALAVRAS-CHAVE: Mário de Andrade; Briga das Pastoras; Folclore
* valterpinheiro@yahoo.com.br

Doutor em Letras (Estudos Linguísticos, Literários e Tradutológicos em Francês) pela Universidade de São Paulo. Professor de Literatura Francesa na Universidade Federal de Sergipe.

ABSTRACT: Among the several areas of cultural intervention to which Mário de Andrade devoted himself with enthusiasm and talent, one of the most noted and studied by criticism is folklore and pop culture. In the vast production of such author about manifestations and traditions of our people, the letters exchanged with Luís da Câmara Cascudo, the "ef our people, the letters exchanged with Luís da Câmara Cascudo, the "ethnographic journey" to the Northern and Northeastern regions of the country and his encompassing studies about Brazllian music and dance are noteworthy. In his fictional work, the Macunaima rhapsody stands out. The author's interest by the Northeastern folklore is also vigorously and poignantly present in an intriguing short story produced in his later years and quite unknown, "Briga das Pastoras" "Row of the shepherdesses"), the narrator of which, an "apprentice tourist" visiting Pernambuco, reveals, likewise Mário, solid methodologic and epistemological knowledge about Ethnology and Ethnography. However Mário left a note indicating his desire that such short story should not be published. Why? The allusion to the "eminently knavish attitude of Brazilian intelligence" at the end of the note seems to point out, in spite of the significant autobiographical traits that permeate such fictional account, the disparity between the author's and the narrator's viewpoints in the aesthetic and ideologic realms.

KEYWORDS: Mário de Andrade; Briga das Pastoras; Folklore 
Talvez como nenhum outro intelectual brasileiro do século XX o tenha feito, o poeta, romancista, professor, crítico de arte, musicólogo, homem de gabinete, jornalista e folclorista Mário de Andrade interveio - ativa e apaixonadamente - nos mais diversos campos de atuação cultural como comprova, aliás, o verso inicial de um de seus mais conhecidos poemas, "Eu sou trezentos" (Remate de Males, 1930). A seu legado artístico e ensaístico nas artes plásticas, na literatura, na música ou na defesa do patrimônio histórico, acrescenta-se outro de cunho não menos importante, o político, pois Mário esteve à frente, de 1935 a 1938, do Departamento de Cultura da Cidade de São Paulo.

O sobrepuja mento das distâncias temporais, espaciais linguísticas e culturais traspassa os versos inicia is do poema supracitado, pelo qual se transita, sem solução de continuidade, da cultura erudita europeia (metonimicamente retratada pelos Pireneus) às raízes popula res brasileiras (representadas pelos caiçaras, mestiços de brancos, índios e negros que habitam regiões litorâneas do Sul e Sudeste do Brasil, e pelo Piauí, estado que, ainda hoje, tem um dos piores índices de desenvolvimento humano do país). Aspecto do projeto estético-ideológico mariodeandradia no - cuja realização mais bem acabada é a narrativa inspirada em estudos etnológicos de Koch-Grünberg Macunaima, que, nos dizeres do antropólogo Darcy
Ribeiro, é um "retrato oblíquo, transverso, do Brasil" -, tal sobrepujamento, ou a "desgeograficação" do Brasil, não seria senão um dos mecanismos de que lançaria mão o escritor para intentar, na e pela literatura, a superação de polarizações (popular versus erudito, selvagem versus civilizado, a trasado versus moderno) que, nas primeiras décadas do século passado, eram ainda subjacentes na obra daqueles que pensavam a cultura brasileira. O a málgama intencional e aparentemente caótico de elementos à primeira vista díspares - no tempo, na distância e nas origens - tem por fim acentuar o caráter paradoxalmente singular e multifacetado de nossa identidade, que seria na perspectiva de Mário, ao mesmo tempo una e trezentos e cinquenta. No bojo dos princípios funda menta is que, como afirmaria o autor em conferência realizada em 1942, nortearam o movimento modernista - a saber: o direito permanente à pesquisa estética, a atualização da inteligência artística brasileira e a estabilização de uma consciência criadora nacional -, sobressai a importância franqueada aos estudos da cultura popular, uma vez que é nela que estariam assentados "os traços de brasilidade", como enfatiza Eduardo Jardim na biografia sobre Mário de Andrade publicada em 2015, em cujo título (Mário de Andrade: Eu sou trezentos: vida e obra) não por acaso aparece o verso ao qual se alude no início do presente texto. 
2. ANDRADE. O turista aprendiz, p.206

3. A primeira versão do conto foi (no 8 , a.12, Rio de Janeiro, 23 de dezembro de 1939). No final do ano seguinte, "Briga das Pastoras" saiu na Revista da Academia Paulista de Letras ( $\mathrm{n}^{\circ} 12$, dez. 1940, p.78-88).

4. Com efeito, encontrou-se apenas um estudo cujo principal objeto de análise fosse o conto de Mário de que se trata aqui: “Casa-grande e mucambo: Mário de Andrade no Pastoril de Maria Cuncáu", de Raquel Illescas Bueno. No artigo, a autora compara "Briga das Pastoras" com passagens extraídas do Turista Aprendiz e Danças Dramáticas do Brasil e aborda uma questão cara - e árdua - para Mário de Andrade: os limites da atitude nacionalista.
A despeito do que declarou em repetidas ocasiões - de que serve de amostra o peremptório "Já afirmei que não sou folclorista", 2 procla mado em coluna assinada no Diário Nacional em 8 de janeiro de 1929 -, o plurivalente escritor paulista no, que se dedicava, tal qual "um tupi tangendo um alaúde”, ao erudito e ao popular, é considerado, de modo inconteste, um dos maiores folcloristas brasileiros do século XX. Imensurável e inestimável é seu legado nesta área, de que se citam, entre outros, Aspectos da Música Brasileira, Namoros com a Medicina, Música de Feitiçaria no Brasil, Danças Dramáticas do Brasil e O Turista Aprendiz, obra póstuma que enfeixa os relatos das "viagens etnográficas" realizadas entre 1927 e 1929 à Amazônia e à região Nordeste, além, é claro, de sua farta publicação em jornais e revistas, destinada múltiplos leitores, e de sua ainda mais rica correspondência, cujo exemplo maior não poderia deixar de ser, neste caso, a entretecida com Luís da Câmara Cascudo. É imprescindível destacar, enfim, que, ao lado de Dina Dreyfus e Claude Lévi-Strauss (que havia m aportado em São Paulo dois anos antes para lecionar na Faculdade de Filosofia, Ciências e Letras da USP, fundada em 1934), Mário de Andrade foi um dos criadores, em 1937, da Sociedade de Etnografia e Folclore, cujo móbil era, ao fim e ao cabo, a busca da identidade nacional, moldada, primordial e incontestavelmente, nas manifestações culturais popula res.

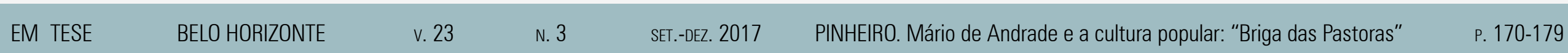

"Briga das Pastoras", que integra a coletânea intitulada Obra Imatura, postumamente publicada em $1960^{3}$, é um conto de Mário de Andrade ainda pouco estudado. ${ }^{4}$ Seu herói-narrador-escritor ${ }^{5}$ relata a devotados leitores um singular episódio de que teria tomado parte - tão logo chegara a um engenho de cana-de-açúcar de um pequeno povoado (situado, como sugerem as referências a Recife, em Pernambuco) - quando jovem. ${ }^{6}$ No almoço com seus anfitriões, condescendente e trivialmente descritos como uma "gente nordestinamente boa, impulsivamente generosa [e] limpa de segundos pensamentos”, o rapaz pusera-se a falar dos "estudos que vinha fazendo sobre o folclore daquelas zonas, o que já ouvira e colhera [e] a beleza daquelas melodias populares”. Estava-se às vésperas do Natal. Disse aos donos da casa, então, que gostaria de assistir a um pastoril. ${ }^{7}$ Desconversou, no entanto, ao ver que a menção, por parte do filho mais moço da família, ao "Pastoril da Maria Cuncáu" desagradara à senhora do engenho. Foi além: prometeu a si mesmo que não iria a tal pastoril. O programa dos dias seguintes - passeios e noites "atravessadas até quase o "nascer da bela aurora", nas quais, na companhia do filho mais velho do casal de proprietários do engenho, teve a oportunidade de ouvir os "cantadores da zona" nos folguedos de Bumba-meu-Boi e nas rodas de coco (com suas toadas "sublimes de grandeza" na "voz la ncinante própria de aboiador[es]") - fez com que, efetivamente, o
5. Não obstante o forte teor autobiográfico da narrativa, não se de Andrade, mas tão-somente ao narrador, cuja declaração, no final do relato, precisa sua condição de escritor: "Sinto é maltratar os meus leitores". "Briga das Pastoras" seria, portanto, um conto da lavra deste narrador-escritor.

6. Sem que se saiba, no decorrer da narrativa, se o fato enunciado é temporalmente distante ou próximo do momento da enunciação.

7. Os pastoris, manifestações folclóricas muito populares no na liturgia da Natividade. Sua form mais corrente é a "lapinha", em que "pastoras" travam um duelo de dança e canto diante do presépio. "O que tem maior significado no pastoril", segundo Renato Almeida "é constituírem as pastoras o elemento básico na função coro, tomado como personagem. [...] Os pastoris se cantam ainda em vários Estados do Norte, mas em plena decadência, e, em pouco tempo, deles só restará a lembrança. Em Pernambuco e no Nordeste em geral, os pastoris são cordōes, feitos em geral aos sábados, do Natal até as vésperas de carnaval, indo as pastoras divididas em duas filas paralelas: uma chamada cordão azul e outra cordão encarnado" (ALMEIDA, Renato. História da Música Brasileira, apud CASCUDO. Dicionário do Folclore Brasileiro, p.683), como ilustra a neste artigo. 


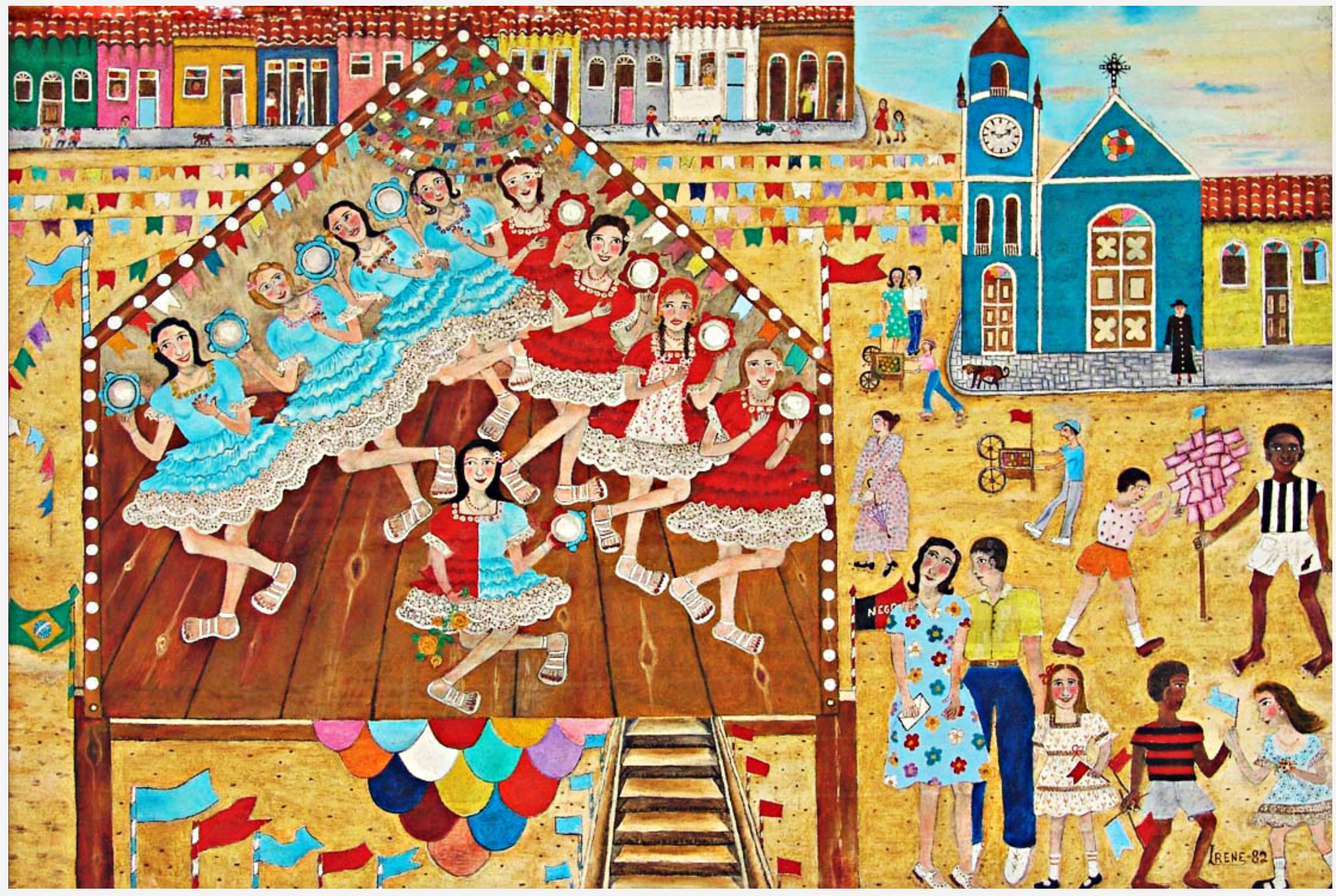


narrador se esquecesse dos pastoris. A chegada do "dia da Festa", contudo, "se impôs violentamente ao [seu] desejo", "como uma necessidade fatal". O jovem decidiu-se, então, a romper o juramento que fizera a si mesmo e a assistir ao Pastoril de Maria Cuncáu. A chegada ao mocambo de Cuncáu merece ser transcrita ipsis litteris:

Chega mos, e logo aquela gente pobre se arredou, da ndo lugar para os dois ricos. Num relance me arrependi de ter vindo. Era a coisa mais miserável, mais degradantemente desagradável que jamais vira em minha vida. Uma salinha pequeníssima, com as paredes arrimadas em mulheres e crianças que eram fantasmas de miséria, de onde fugia um calor de forno, com um cheiro repulsivo de sujeira e desgraça. Dessa desgraça horrível, humanamente desmoralizadora, de seres que nem siquer se imaginam desgraçados mais. Cruzavam-se no teto uns cordões de bandeirolas de papel de embrulho, que se ajuntavam no fundo da saleta, caindo por detrás da lapinha mais tosca, mais ridícula que nunca supus. [...] Dançando e cantando, aliás com a sempre segura musicalidade nordestina, eram nove mulheres, de vária idade, em dois cordões, o cordão azu e o encarnado da tradição, com mais a Diana ao centro. O que cantavam, o que diziam não sei, com suas toadas sonolentas, de visível importação urbana, em que a horas tantas julguei perceber até uma marchinha carioca de carnaval. ${ }^{8}$
A encenação a que assistia o desnorteava. Tudo, ali, era sórdido. Repugnado pela "visão de miséria degradada" de um ambiente que, ademais, não comportava "nenhum interesse folclórico”, o rapaz decidiu furtiva e discretamente deixar o local. Maria Cuncáu, divisando seu intento, interpelou-o, pedindo-lhe uma gratificação para a lapinha. O que se segue é um misto de "comiseração" e "horror":

Sinto é maltra tar os meus leitores. Este conto que no princípio parecia preparar algum drama forte, e já está se tornando apenas uma esperança de dramazinho miserável, vai acabar em plena mesquinharia. Quando puxei a carteira, decidido a dar vinte mil-réis, a piedade roncou forte, tirei com decisão a única nota de cinquenta que me restava da noite e pus no pires. Todos viram muito bem que era uma nota... 9

Ao avistarem o dinheiro no pires, duas pastoras (dentre as quais Maria Cuncáu) deram início a uma "luta muda, odienta [e] cheia de guinchos" pela posse do dinheiro. Os dois moços deixaram o moca mbo. Ao encalço deles, no entanto, veio ligeira e desavergonhadamente Maria Cuncáu. O narrador, constrangido com um novo pedido da desvalida pastora, ainda lhe deu mais alguns trocados.

O entusiasmo do autor de Macunaíma por assuntos relativos ao folclore, patente por suas "viagens etnográficas"
ANDRADE. Obra imatura, p.181
EM TESE
BELO HORIZONTE 
10. VALENTINI. Um laboratório de antropologia: o encontro entre Mário de Andrade, Dina Dreyfus e Claude Lévi-Strauss (1935-1938), p.45.

11. Oneyda Alvarenga, no texto introdutório ("Explicacões") de Os Cocos, afiança: "Pelo que se sabe de Mário de Andrade na época de sua maior atividade como pesquisador de folclore, seu interesse residia então, antes de mais nada, em obter documentos musicais populares que ajudassem os compositores brasileiros a fixarem as bases nacionais da nossa música artística. Suas pesquisas começaram como um trabalho fundamentalmente de músico que não pretendia considerarse folclorista." (ANDRADE. Os Cocos, p.16). Raquel Illescas Bueno, no ensaio intitulado "As excursões etnológicas de Mário de Andrade e Lévi-Strauss", vai um pouco além: "Documenta e estudar as manifestações culturais desconhecidas dos iminêros - acreditava-se - na suas prioridades descle os anos 1920. Suas vias dens longas foram planejadas para que pudese assistir cirandas e outras festa locais na Amazônia. No Nordeste preencheu vários cadernos com anotações da música e demais particularidades de cada dança dramática. Documentou detalhadamente apresentações de cheganças, pastoris e diversas festas do boi." (p.219). ao longo da década de 1920, é fortalecido, no decênio seguinte, nas ações promovidas pelo Departamento de Cultura, dentre as quais se notabilizam a formação intitulada "Instruções práticas para pesquisa de Antropologia Física e Cultural" ministrada por Dina Dreyfus em 1936 (posteriormente conhecida como "Curso de Etnografia"), cujo eixo era o detalhamento de "técnicas e métodos de coleta e registro para a constituição de coleções e arquivos etnográficos e folclóricos", ${ }^{10}$ os giros pelo interior paulista ao lado de Claude Lévi-Strauss (nomeados pelo autor de Tristes Tropiques de "ethnographie du dimanche") e a Missão de Pesquisas Folclóricas projetada por Mário, cujo intento era, justamente, reunir documentos alusivos ao folclore no Nordeste brasileiro. ${ }^{11}$ Muitas das questões apresentadas no curso de Dina Dreyfus serão recorrentes em artigos publicados em jornais e revistas e ta mbém aparecerão na correspondência do escritor paulistano. Vale destacar, neste ponto, a crítica que Mário de Andrade faz, em carta de 09 de junho de 1937, ao "jeito anticientífico do estudo" de Câmara Cascudo, cujos trabalhos, afirma, pecam pela "ausência de dados sobre como foram colhidos os dados, de quem etc.". Por fim, Mário recomenda ao amigo:

Sei que você pode fazer isso e mais. Você tem a riqueza folclórica aí passando na rua a qualquer hora. Você tem todo os seus conhecidos e amigos do seu Estado e Nordeste pra
EM TESE pedir informações. Você precisa um bocado mais descer dessa rede em que você passa o tempo inteiro lendo até dormir Não faça escritos ao vai-vem da rede, faça escritos caídos das bocas e dos hábitos que você foi buscar na casa, no mocambo, no antro, na festança, na plantação, no cais, no boteco do povo. Abandone esse ânimo aristocrático que você tem e enfim jogue todas as cartas na mesa, as cartas de seu valor pessoal que conheço e afianço, em estudos mais necessários e profundos. ${ }^{12}$

Mais do que a transcrição, módica e concisa, amoldada ao gênero conto, de refrãos de cocos "bo[ns] de sapatear" ("Olê, rosêra, / Murchaste a rosa"13 e "Vô m'imbora, vô m’imbora / Pá Paraíba do Norte!...”), ou o detalhamento, sob roupagem acadêmica, dos pastoris, o que se distingue, em "Briga das Pastoras" - narrativa que, segundo o apontamento deixado pelo autor no final do manuscrito, pertenceria, "como espírito, a essa atitude de inteligência nacional que [ele] consider[ava] eminentemente cafajeste" -, são o registro da metodologia empregada na coleta de documentos e o desencantamento do narrador ao assistir, in loco, a uma manifestação que, como já mencionado, não apresentava, por suas ostensivas marcas de "importação urbana" e pela "visão de miséria degradada", "nenhum interesse folclórico". ${ }^{14}$ A sucessiva menção a "estudos [que] haviam naturalmente de [prendê-lo] noites fora de casa",
12. CASCUDO. Câmara Cascudo e Mário de Andrade: cartas 1924 1944, p. 296.

13. Cantiga cujos versos são citados em outras obras de Mário, como $O$ Cocos (p.79, com partitura inclusa).

14. Incômodo, diga-se de passagem, registrado pelo autor na descrição Pastoril de Palmares, que dou Pasti, é bem característico dou profanidade. Muito embora ele não esteja provavelmente completo, as referências religiosas são absolutamente mínimas e são absolutamente minimas e protótipo do Pastoril popularesco, mesclado em tudo, com músicas desta e outra procedência, umas nacionais, outras estranhas, cenas mal emaranhadas, às vezes sem nenhuma ligação entre si, meio revista de teatro, meio revista de... pernas, de cabaré. Não é mais sequer semierudito, mas não chega a ser popular. $E$ daquele popularesco urbano cujo cosmopolitismo dificilmente chega a ter valor etnográfico." (ANDRADE. Danças Dramáticas do Brasil, p.353). 
a conversas e escutas de "empregados", "informantes" e "cantadores da zona" e a comentários em que subjazem conhecimentos técnicos sobre o cantar nordestino aponta manifesta e distintamente os procedimentos de que se valia o narrador para recolher e compilar os dados coligidos (tais como a elaboração de fichas e a inclusão de leigos no grupo de pesquisadores especializados) e põe em evidência reitere-se, o efetivo propósito da excursão em Perna mbuco.

Muitos dos procedimentos metodológicos elencados por Mário de Andrade na carta a Câmara Cascudo desvelam-se, pois, em "Briga das Pastoras". Se, na opinião de Mário lançada na já mencionada nota final do manuscrito, o conto é fraco, "literário por demais" (e por isso não mereceria ser publicado), a na rrativa vale, todavia, por mostrar, de forma ficcional, como deveriam proceder aqueles que desejassem estudar a cultura popular.

O autor (que, como já dito, havia anos antes veementemente a firmado não ser folclorista) volta rá à questão da coleta em 1936 em um artigo publicado na revista Síntese Ao descrever a difícil situação da Etnografia no Brasil, combate o excesso de teoria e a "pouca seriedade na colheita dos documentos” e proclama:

Nós não precisamos de teóricos, os teóricos virão a seu tempo. Nós precisamos de moços pesquisadores, que vão à casa do povo recolher com seriedade e de maneira completa o que esse povo guarda e rapidamente esquece, desnorteado pelo progresso invasor. ${ }^{15}$

Mas é necessário aos moços que queiram realizar esse trabalho de enorme benemerência, que aprendam a colher, para depois colher. Não é amadoristicamente se meterem no meio do povo, de lápis em punho, perguntando coisas, rindo das aparentes tolices que escutam, assustando o povo e sendo enganado por ele. É preciso aprender a lidar com o povo, e saber o que deverá ser colhido, como e para quê. ${ }^{16}$

De qual perspectiva o herói-narrador - e sujeito-pesquisador - de "Briga das Pastoras" examina (e posteriormente noticia a seus leitores) as manifestações a que assiste? Distingue, como em princípio se espera, seu local de fala (de um "homem do sul" em "viagem etnográfica", turista aprendiz como seu criador) daquele ocupado pelos sujeitos-objetos de sua investigação (que, conquanto possuam a voz encantatória do canto, não têm o poder da palavra) e sabe distanciar-se deles critica mente?

Para responder a essas questões, não se pode deixar de aludir à "atitude de inteligência nacional eminentemente cafajeste" mencionada pelo autor em nota supratranscrita (de que se extrai, ainda que obliqua mente, a resposta - negativa - ao segundo ponto assinalado no parágrafo anterior)
15. Como as tais toadas "de visível importação urbana" que o narrador de "Briga das Pastoras" identificara no mocambo de Cuncáu?

16. MORAES. Mário, Otávio: Cartas de Mário de Andrade a Otávio Dias Leite (1936-1944), p.108-109.

\begin{tabular}{|c|c|c|c|c|}
\hline EM TESE & BELO HORIZONTE & v. 23 & N. 3 & SET.-DEZ. 2017 \\
\hline
\end{tabular}

Teoria, Crítica Literária, outras Artes e Mídias 
17. Raquel Illescas Bueno, em "Casagrande e mucambo: Mário de grandrade no Pastoril de Maria Cuncáu", declara: "O narrador de 'Briga das pastoras' é solidário com os sofrimentos abafados da senhora de engenho" (p.99), solidariedade tanto mais digna de nota se se constata que navega contra a corrente do patriarcalismo local. E preciso que se atente,

não obstante, ao fato de que esse laço se tece no interior da mesma classe social, sem que haja, por conseguinte, o sobrepujamento de profundas diferenças sociais a despeito da desigualdade de origem, gênero e geração que encerra).
Mário decerto reconhece o fato de que o esforço de integração da cultura popular pela cultura letrada brasileira - mais especificamente no campo da literatura - ainda se faz, ao menos até meados da década de 1930, na e pela perspectiva das classes dirigentes. Ao a firmar que "aquela gente nordestinamente boa" era "limpa de segundos pensamentos" (sua pureza de caráter seria decorrente da falta de senso crítico?) ou suposta mente deplorar a sordidez do moca mbo de Cuncáu menos pela pobreza em si, resultado de um quadro de desigualdade social acaçapante (fenômeno de que era cônscio e contra o qual talvez nada tenha feito senão lançar trocados a indigentes), do que pela perda do interesse folclórico do festejo miseravelmente degradado que se lhe impunha à vista, o narrador mariodeandradiano secunda clichês e termina por ratificar e legitimar, em seu relato, o discurso dominante. ${ }^{17} \mathrm{~A}$ cafajestice a que se refere o autor multiplica-se se for acrescentada ao exame do estra to ideológico a apreciação da esfera estética, em que sobressai o emprego, em conto escrito no crepúsculo dos anos trinta - momento em que a a tualização da inteligência artística brasileira e a estabilização da consciência criadora nacional já haviam sido alcançadas -, de uma roupagem real-naturalista de ares oitocentistas (embora essa seja, na opinião do a utor expressa na nota adicionada ao manuscrito, a melhor réussite do conto)
Tais contrassensos não são inéditos na obra de Mário de Andrade, revelando-se, por conseguinte, como preocupações recorrentes do a utor. A consciência de parcialidade (ou de um precário distanciamento crítico) já havia aparecido, com aspecto distinto, em "Brasília", conto escrito em $1921,{ }^{18}$ cujo narrador, um diplomata francês em missão no Rio de Janeiro, farto das "sábias carícias das mulheres francesas", almeja deleitar-se com uma "exótica selvagem brasileira". No final do relato (no decorrer do qual, assinale-se, se entremeiam impiedosos comentários sobre a alta burguesia paulista e carioca que, no contínuo e insano esforço de reproduzir em solo pátrio os costumes e os valores europeus, se deixa enganar por falsificações), descobre-se que a mulher brasileira com a qual se envolvera era igualmente uma cópia, uma imitação. Ao fim e ao cabo, a visão europeizada (que, portanto, seria - acreditava-se - universal, racional e exata) induz o diplomata ao erro.

Em “Briga das Pastoras”, o equivocado da história parece ser o sujeito-pesquisador, cuja decepção, resultado de sua ânsia por assistir a manifestações cultura is "autênticas”, a salvo de "importações urbanas", frustrada pela sobreposição da cultura citadina à rural no interior de uma sociedade periférica (como é a brasileira), decorre de seu alheamento - se não total, ao menos parcial - à "assimetria de fluxos culturais hegemônicos"19 em níveis nacional
18. E despontaria ainda nos Contos de Belazarte, lançados em 1934.

19. Expressão cunhada por Benjamin Abdala Junior em Literatura Comparada \& Relações Comunitárias, Hoje.

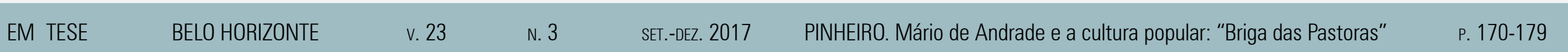

Teoria, Crítica Literária, outras Artes e Mídias 
20. BOTELHO. De olho em Mário de Andrade: uma descoberta intelectual e sentimental do Brasil, p. 100

21. Julga-se útil reproduzir por Aprendiz (dassagem do Turista a quarz (dato ànei (não transcrita) do trecho supracitado: "Manhã de compras, passagens, caceteações, peles de lontra, mercado, como sempre, essa maior ventura de Belém... Coisas de índios... Enfim compro algumas, é meio besta. A falta brasileira de organização tamanha que tudo o que vendem dos índios, no mercado de Belém, é legítimo. É tudo bastante feio, sem valor, usado. Inda não teve quem se lembrasse que è falsificando que a gente consegue tornar estas coisas de mais valor, não so fazendo mais bonito e mais bem feito que os índios, como valorizando as coisas deles, por torná-las legitimas e mais raras. É o documento falso que torna o verdadeiro, legítimo." (ANDRADE. Oturista aprendiz, p.164).

22. MAROUES. Briga das Pastoras e outras histórias: Mário de Andrade e a busca do popular, p.132-133. e regional. Neste aspecto, o diplomata francês, o turista aprendiz sulista e boa parte da intelligentsia brasileira caminham pari passu (em sentido diverso, todavia, daquele adotado pelo autor, cuja "empatia pelo 'popular", ${ }^{20}$ como assinala André Botelho, "não se dilui num fetiche [por] suposta $[\mathrm{s}]$ 'autenticidade[s]”. ${ }^{21}$

Portanto, a despeito dos significativos traços autobiográficos que permeiam a narrativa, o narrador de "Briga das Pastoras" não se nos afigura como um alter ego de Mário de Andrade. Ao contrário: o encanto pela cultura popular, que la nça a mbos em estudos folclóricos de fôlego (marcados, com efeito, pela adoção de princípios metodológicos e epistemológicos similares), não se superpõe, como atesta a anotação do autor registrada nos originais, a perspectivas - ideológicas e estéticas (cafajestes ou não) - que os distanciam. No ensaio que encerra sua antologia de contos de Mário de Andrade recém-publicada, Briga das Pastoras e outras histórias, Ivan Marques afirma:

[O conto que dá nome à coletânea] põe em evidência o abismo existente entre o saber acumulado ao longo de anos por um viajante interessado na cultura do povo (mas bem abrigado e alimentado na casa-grande da fazenda) e o conhecimento advindo do contato com a realidade adversa em que vive esse mesmo povo. ${ }^{22}$
Esse abismo consubstancia-se em uma voz única, que, embora sensível, não faculta a palavra às demais personagens do conto. Busca incansável de Mário de Andrade, uma voz que se funda às de personagens populares (sem confundir-se com elas, no entanto) só elevar-se-á nos Contos Novos, publicados postumamente.

\section{REFERÊNCIAS}

ABDALA JUNIOR, Benjamin. Literatura Comparada \& Relações Comunitárias, Hoje. São Paulo: Ateliê Editorial, 2012.

ANDRADE, Mário de. 0 turista aprendiz. Belo Horizonte: Itatiaia 2002. 980

Obra Imatura. São Paulo: Martins; Belo Horizonte: Itatiaia,

Os Cocos. São Paulo: Duas Cidades; Brasília: Instituto Nacional do Livro, 1984.

Danças Dramáticas do Brasil. Belo Horizonte: Itatiaia; Brasília: Instituto Nacional do Livro, 1982.

BOTELHO, André. De olho em Mário de Andrade: uma descoberta intelectual e sentimental do Brasil. São Paulo: Claro Enigma, 2012.

BUENO, Raquel lllescas. As excursões etnológicas de Mário de Andrade e Lévi-Strauss. FronteiraZ, nº 17, dez. 2016, p.215-224.
EM TESE
BELO HORIZONTE
v. 23
N. 3
SET.-DEz. 2017
PINHEIRO. Mário de Andrade e a cultura popular: "Briga das Pastoras"
P. $170-179$

Teoria, Crítica Literária, outras Artes e Mídias 
Casa-grande e mucambo: Mário de Andrade no Pastoril de Maria Cuncáu. Guavira Letras, nº 23, jul. / dez. 2016, p.90-100.

\section{CASCUDO, Luís da Câmara. Câmara Cascudo e Mário de}

Andrade: cartas 1924-1944. Pesquisa documental, iconográfica,

estabelecimento de texto e notas (organizador): Marcos Antonio de Morais. São Paulo: Global, 2010.

Dicionário do Folclore Brasileiro. Rio de Janeiro: Ediouro,

JARDIM, Eduardo. Mário de Andrade: Eu sou trezentos: vida e obra. Rio de Janeiro: Edições de Janeiro, 2015.

MAROUES, Ivan. O apaixonado da coisa popular. In: ANDRADE, Mário de. Briga das Pastoras e outras histórias: Mário de Andrade e a busca do popular. Organização: Ivan Marques. São Paulo: Edições SM, 2016, p.121-134.

MORAES, Marcos Antonio de (organização, introdução e notas). Mário, Otávio: Cartas de Mário de Andrade a Otávio Dias Leite (1936-1944). São Paulo: IEB-USP / Oficina do Livro Rubens Borba de Moraes / Imprensa Oficial, 2006.

RIBEIRO, Darcy. Liminar - Macunaíma. In: ANDRADE, Mário de Macunaíma, o herói sem nenhum caráter. $2^{\mathrm{a}}$ edição. Ed crítica de Telê Porto Ancona Lopez. Coleção Arquivos, Unesco, 1996, p.XVII-XXII.

VALENTINI, Luísa. Um laboratório de antropologia: o encontro entre Mário de Andrade, Dina Dreyfus e Claude Lévi-Strauss (1935-1938). São Paulo: Alameda, 2013.
REFERÊNCIA ICONOGRÁFICA

"Pastoril", pintura de Irene Medeiros. Disponível em http:// www.overmundo.com.br/overblog/o-sangue-alagoano-e-azul-eencarnado. Acesso em 01/06/2017.

Recebido em: 01-06-2017. Aceito em: 02-05-2018 